\title{
Interdecadal changes of the ISO and the associated TC/submonthly Wave Pattern in the Western North Pacific
}

\author{
Ken-Chung $\mathrm{Ko}^{1, *}$, Huang-Hsiung $\mathrm{Hsu}^{2}$, and Jyun-Hong Liu ${ }^{1}$ \\ ${ }^{1}$ Department of Geography, National Kaohsiung Normal University, Kaohsiung City, Taiwan \\ ${ }^{2}$ Research Center for Environmental Changes, Academia Sinica, Taipei City, Taiwan
}

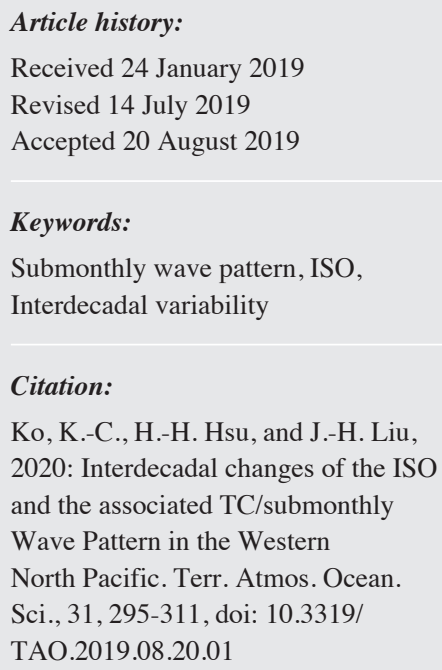

Citation:

Ko, K.-C., H.-H. Hsu, and J.-H. Liu, 2020: Interdecadal changes of the ISO and the associated TC/submonthly Wave Pattern in the Western North Pacific. Terr. Atmos. Ocean. Sci., 31, 295-311, doi: 10.3319/ TAO.2019.08.20.01

\begin{abstract}
Interdecadal variability of northward-propagating ISOs from July to September is examined by dividing the 32 years into 1979 - 1993 and $1994-2010$. The enhanced easterly anomalies in 1994 - 2010 could increase the steering flow for the submonthly wave pattern and TCs. Therefore, the propagation routes for TCs and submonthly wave patterns were pushed farther westward toward eastern China in $1994-2010$ instead of slowly migrating northward to Japan in 1979 - 1993. By separating the background flow into the climatological mean and ISO components, a sensitivity study of the barotropic interaction is conducted when switching the background flow of the other epoch. The results show that the enhancement of the subtropical anticyclone in the later epoch changes the distribution of the background easterly flow and thus the barotropic conversion maximum between the submonthly perturbations and climatological circulation was displaced westward. The strengthening of the ISO background fields in the later epoch enhances the barotropic interaction between the ISO and submonthly perturbations. Thus in the westerly phase of the later epoch, the enhanced ISO cyclonic anomaly favors the barotropic conversion to intensify. The positive areas of interdecadal changes for the barotropic conversion between the submonthly perturbations and the climatological mean fields are co-located with the positive changes due to the ISO background fields where the wave pattern and TCs move further westward in the later epoch. Therefore, the interdecadal impacts by the climatological mean fields and ISO on the energy conversion jointly favor the development of the wave pattern and TCs.
\end{abstract}

\section{INTRODUCTION}

The northward-propagating intraseasonal oscillation (ISO) plays an important role in affecting the East Asian weather and circulation patterns in summer (Wang and Rui 1990). Using pentad mean anomaly maps of outgoing longwave radiation (OLR), Wang and Rui (1990) found a considerable amount of northward-propagating ISOs in the Indian Ocean and western Pacific. Most of the northwardpropagating ISO events prevailed from the equatorial western Pacific to the East Asian monsoon region in summer.

One of the important issues in the ISO studies is the inter-decadal variability of the ISO. Kajikawa et al. (2009) detected a change of the spectral peaks of the northwardpropagating ISOs around 1993/94. The significant spectral

\footnotetext{
* Corresponding author

E-mail:kko@nknu.edu.tw
}

peak of the ISO in 1979 - 1993 exhibited a longer period (64 days) than that (47 days) in the 1994 - 2007 epoch. A merging process of a westward moving intraseasonal convection from east of the Philippines to the South China Sea was observed in 1979 - 1993 but not in the later epoch. In addition, the longer period in 1979 - 1993 could be due to the merging process of the westward moving ISO approaching the South China Sea. The 1979 - 1993 epoch happened to be the same as the study period as in Hsu and Weng (2001) that found northwestward-propagating signals in the Philippines-South China Sea area. In an extension study, Kajikawa and Wang (2012) detected the onset date change of the South China Sea summer monsoon for the aforementioned two epochs. The onset date for 1979 - 1993 is about two weeks later than that in 1994 - 2008. The aforementioned studies suggest that the impact of the interdecadal variability on the ISO is an 
important issue. The decadal climate shift of the summertime monsoon circulation in mid-1990s was also examined by Kwon et al. (2007). They found a distinct increase in precipitation near southeastern China in 1994 - 2004 compared with that in $1979-1993$. The year of the climate shift is similar to that as in Kajikawa et al. (2009).

In addition to the aforementioned studies, Chen and Chen (2011) investigated the interdecadal variability of the summer rainfall in Taiwan from 1950 to 2008 . They found that the interdecadal variability of the TC rainfall in Taiwan was closely related to the weakening of the subtropical high that would change the southeasterly or southerly flow and force TCs to move near Taiwan. Therefore, the TC rainfall near Taiwan experienced an increasing trend.

Another issue affecting the East Asian climate is the quasi-periodic wave pattern. A 3-8-day synoptic wave discovered by Lau and Lau (1990) generally propagated northwestward from the tropical western North Pacific (WNP) to southern China. This synoptic wave was usually accompanied by TCs in its cyclonic anomalies (Chang et al. 1996). These TCs underwent the straight-moving propagation route along the monsoon trough in East Asian summer. By contrast, in a composite study, Ko and Hsu (2006) detected a wave pattern that recurred every 7 to 30 days, and this submonthly wave pattern generally propagated northnorthwestward from the equatorial western North Pacific to the East China Sea and then turn northeastward to higher latitudes. TCs often emerged in the cyclonic anomaly and followed the wave pattern to undergo a recurving path.

Multi-scale interaction studies also attracted much attention in recent years. Maloney and Dickinson (2003) examined kinetic energy of TC-type disturbances after dividing them into two ISO phases (westerly and easterly) in the western North Pacific. They found the ISO westerly cases exhibited more energetic patterns than that in the easterly phase. Ko and Hsu (2009) adopted a similar technique as in Maloney and Dickinson (2003) on the submonthly wave pattern cases and found that the ISO westerly phase tended to enhance the monsoon trough and became a favorable environment for the submonthly wave pattern and TCs to develop. By contrast, the wave pattern and TCs in the easterly phase were weaker and poorly organized. The aforementioned studies indicate that the ISO can influence smallerscale and higher-frequency phenomena.

Following the interaction studies between the ISO and submonthly wave pattern as in Ko and Hsu (2009), Ko et al. (2012) conducted an energetic study using the kinetic energy equation. The results showed that the barotropic conversion term dominated and the background flow in the ISO westerly phase supplied more kinetic energy to the perturbations than that in the easterly phase. However, after replacing the background flow by the 30-80-day filtered flow, the ISO supplied kinetic energy to the submonthly disturbances in the westerly phase but gained kinetic energy from them in the easterly phase (Ko and Hsu 2014). Therefore, two way interactions exist between the ISO and submonthly wave patterns.

Because the ISO tended to modulate higher-frequency phenomena (Maloney and Dickinson 2003; Ko and Hsu 2009), changes in the ISO between the two epochs would influence the submonthly fluctuations. The present study investigates the interdecadal variability of the ISO following the change in 1993/94 identified by Kajikawa et al. (2009) and Kajikawa and Wang (2012). We further explore how this change in ISOs modulates the submonthly wave pattern and TCs. Interactions between the inter-decadally varying background flow and perturbations are also addressed. The rest of this paper is organized as follows: Section 2 describes the data and analysis procedures. Characteristics of the background flow for the climatological mean and intraseasonal band for two epochs are discussed in section 3 . The propagating behavior of the submonthly wave pattern is shown in section 4 and a kinetic energy study related to this interdecadal change and a sensitivity test about the background flow are examined in section 5 . Section 6 presents the summary.

\section{DATA AND ANALYSIS PROCEDURES}

The datasets used in the present study include the circulation data from National Center for Environmental Prediction (NCEP) re-analysis I (Kalnay et al. 1996), and the outgoing longwave radiation (OLR) from NOAA. Both datasets are available in a $2.5^{\circ} \times 2.5^{\circ}$ grid and from 1979 to 2010. The NCEP re-analysis I contains 6-hourly temperature, humidity, horizontal wind, vertical velocity, and geopotential height at 12 vertical levels. Daily OLR data are also used. The horizontal winds are used to construct the streamfunction. The TC data are from the Joint Typhoon Warning Center (JTWC) to investigate links between the large-scale phenomena and TCs.

Cases are selected for submonthly (6-20-day) and ISO (30-80-day) events in a similar way as in Ko and Hsu (2009). Readers are referred to the paper for details. The procedures are briefly described here: The submonthly cases are selected based on the maxima of the 6-20-day filtered time series of 850-hPa vorticity averaged over the base region (20 $-35^{\circ} \mathrm{N}, 120-140^{\circ} \mathrm{E}$ ) near Taiwan and Japan (Ko and Hsu 2009). The peak time of a case is denoted as Day 0. A submonthly case with TC (TC/submonthly) is further defined when at least one TC appears in the base region between Day -1 and Day +1 of a selected sub-monthly case. The TC/ submonthly cases are further classified into two categories: ISO westerly and easterly phases. A TC/submonthly case is defined as a westerly (easterly) case if the 30 - 80 filtered zonal wind averaged over the ISO base region (5 $15^{\circ} \mathrm{N}, 100-125^{\circ} \mathrm{E}$, as in $\mathrm{Ko}$ and Hsu 2009) is greater than $1.5 \mathrm{~m} \mathrm{~s}^{-1}$ (less than $-1.5 \mathrm{~m} \mathrm{~s}^{-1}$ ) at the same time as Day 0 of the TC/submonthly case. The $\pm 1.5 \mathrm{~m} \mathrm{~s}^{-1}$ thresholds are 
approximately \pm 0.5 standard deviation of the 30-80-day filtered zonal wind time series. The resultant number of TC/ submonthly cases is 26 and 13 for the ISO westerly and easterly phases in $1979-1993$ and 25 and 20 for the ISO westerly and easterly phases in 1994 - 2010, respectively.

An algorithm proposed by Rodionov (2004) is applied to identify climate regime shifts in a time series. This method is designed to detect significant changes when using a sequential running means of a certain period. A regime shift is detected when the variance in the period before the year is significantly different from that after the year. In this study, an 11-year running period is used to perform the regime shift detection scheme. This method is efficient in detecting significant changes in a time series and has been proved useful as in Lo and Hsu (2008).

In order to study the interaction between the ISO and TC/submonthly wave pattern, the barotropic conversion term adopted following the kinetic energy equation as in Ko et al. (2012) is written as follows:

Barotropic conversion $(\mathrm{kp})=$

$$
-\overline{u^{\prime 2}} \frac{\partial \bar{u}}{\partial x}-\overline{u^{\prime} v^{\prime}} \frac{\partial \bar{u}}{\partial y}-\overline{u^{\prime} v^{\prime}} \frac{\partial \bar{v}}{\partial x}-\overline{v^{\prime 2}} \frac{\partial \bar{v}}{\partial y}
$$

Where the overbars represent the average of the unfiltered fields over the 10-day period centered at Day 0 for all cases, with the primes the 6-20-day filtered fields. The first two terms on the right hand side are dominant terms according to Ko et al. (2012). In a similar manner, the overbars are replaced by the average of the 30-80-day fields over the 10-day period centered at Day 0 for all cases (Ko and Hsu 2014), and the barotropic conversion becomes the interaction between the submonthly and the ISO fields.

\section{SUBMONTHLY SIGNALS AND INTERDECADAL CHANGES OF THE ISO}

Figure 1a shows a vorticity variance maximum in the area between Taiwan and Japan. The box area in Fig. 1a, which is similar to the base region as in Ko and Hsu (2006, 2009), is chosen as a base region in detecting periodic signals, and the spectrum of the area-averaged vorticity is shown in Fig. 1b. A spectral maximal area with periods between 6 and 20 days is observed from mid-July to October with the strongest amplitude appearing between late July and September. The spectral characteristics were similar to that in Ko and Hsu (2006, 2009).

The 3-month (July to September) averages of the squared 30-80-day zonal wind for the box area $\left(5-15^{\circ} \mathrm{N}\right.$, $100-125^{\circ} \mathrm{E}$ ), which was also the box used for selecting the ISO events as in Ko and Hsu (2009), is shown in Fig. 2a. This quantity (squared 30-80-day zonal wind) was chosen to yield the magnitude of the 30-80-day zonal wind. To avoid stronger interannual fluctuations, a 3-yr running mean was applied to the series before performing the regime shift technique. A regime shift index (blue bar) developed by Rodionov (2004) is adopted here to pinpoint jumps of variance before and after any specific year in order to illustrate the interdecadal variability of the ISO. Apparently, the trend of
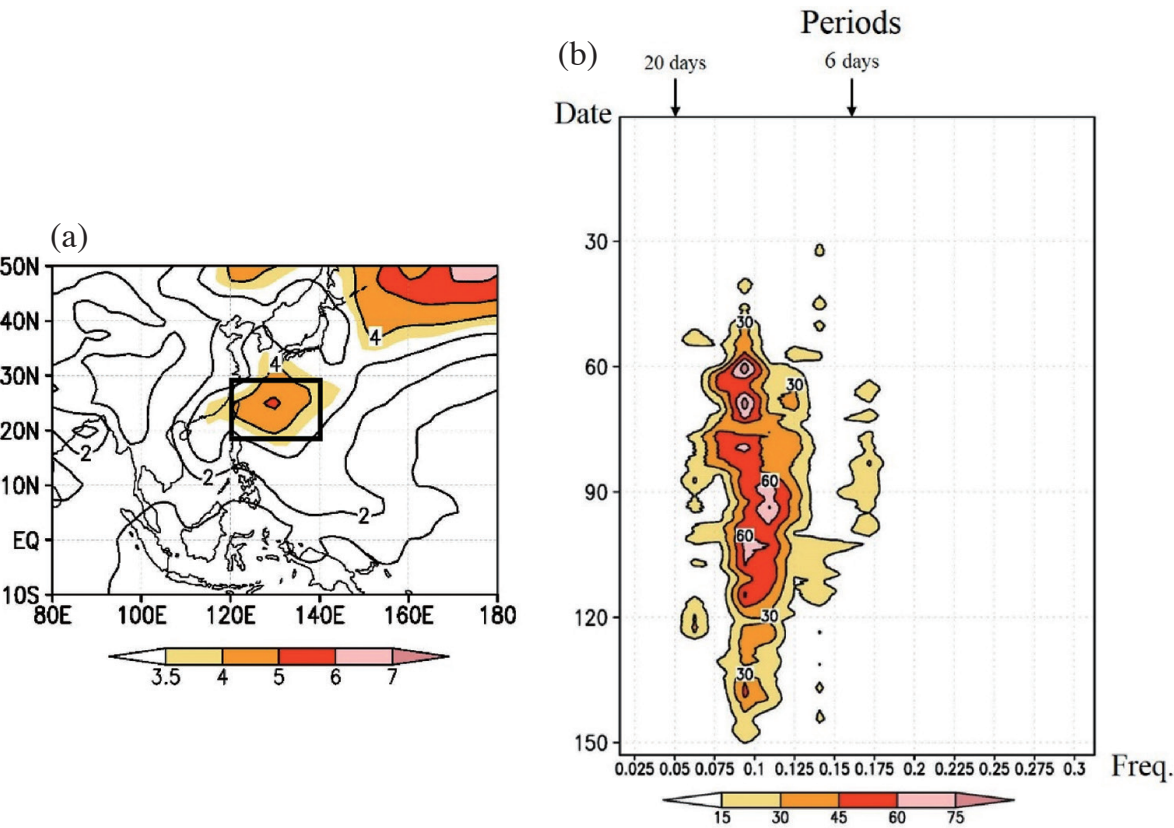

Fig. 1. (a) variance of vorticity for three months (July to September) from 1979 to 2010 (contour interval $1 \times 10^{-10} \mathrm{~s}^{-2}$ ), and (b) the moving spectrum for the vorticity averaged over $20-30^{\circ} \mathrm{N}, 120-140^{\circ} \mathrm{E}$ [the box area in (a)]. The contour interval is $1 \times 10^{-9} \mathrm{~s}^{-2}$. The $\mathrm{x}$-axis is the frequency $(1 /$ period in days) and the $y$-axis is the day starting from June 1. All the spectra are ensemble-averaged over those 32 years (1979 - 2010). 
(a) 30-80 day $\mathrm{u}^{\wedge} 2$

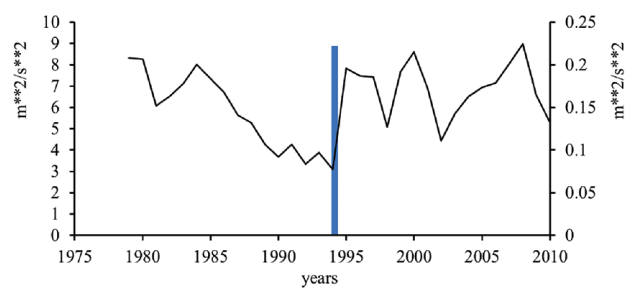

(c) Mean of 1979-1993

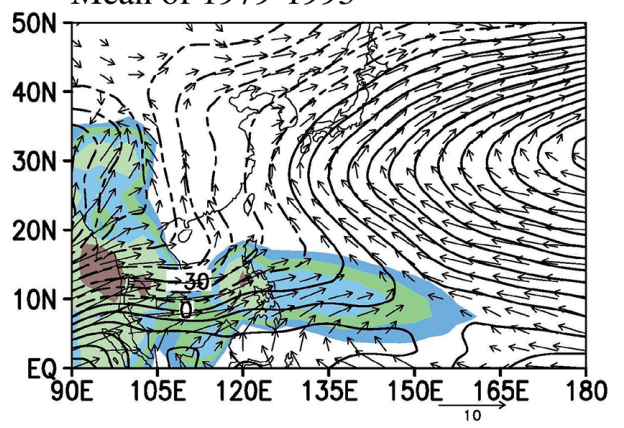

(b) 6-20 day vor^2

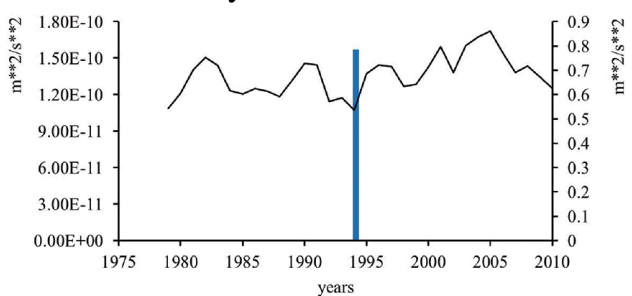

(d) Mean of 1994-2010

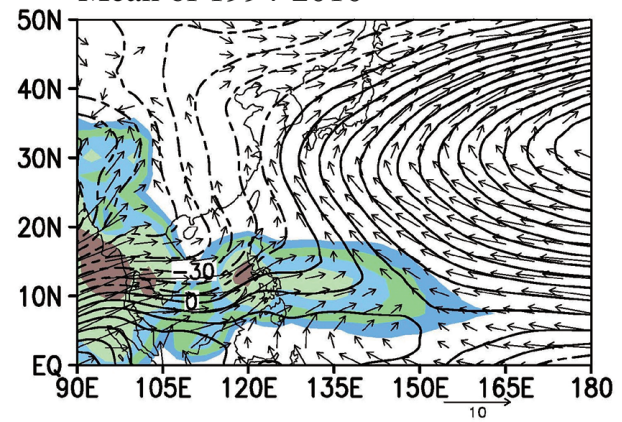

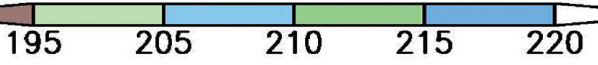

(e) Diff between 1994-2010 and 1979-1993
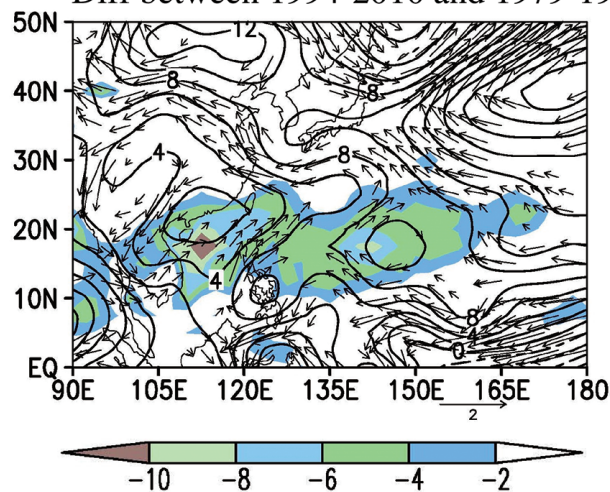

Fig. 2. Three-month averages (July to September) from 1979 to 2010 for (a) the squared 30-80-day filtered 850 hPa zonal winds (ms-2) averaged over $5^{\circ}-15^{\circ} \mathrm{N}, 100^{\circ}-125^{\circ} \mathrm{E}$, and (b) the squared 6-20-day filtered vorticity $\left(\mathrm{s}^{-2}\right)$ averaged over $20^{\circ}-30^{\circ} \mathrm{N}, 120^{\circ}-140^{\circ} \mathrm{E}$. The blue bar represents the regime shift indices (second y-axis). Climatological mean state (July to September) $850 \mathrm{hPa}$ streamfunction (contour), winds (m s $\mathrm{s}^{-2}$ ) and OLR (shaded, $\mathrm{W} \mathrm{m}^{-2}$ ) for (c) 1979 - 1993, (d) 1994 - 2010, and (e) mean state difference map between 1994 - 2010 and 1979 - 1993. The contour interval is $10 \times 10^{5} \mathrm{~m}^{2} \mathrm{~s}^{-1}$ for the streamfunction and is $2 \times 10^{5} \mathrm{~m}^{2} \mathrm{~s}^{-1}$ for the difference streamfunction. Only winds exceeding the $95 \%$ confidence levels are shown. 
the suqared intraseasonal zonal wind changed in 1994, and the amplitude of the fluctuations for the suqared intraseasonal zonal wind increased after 1994. This change between two epochs reflects the interdecadal modulation of intraseasonal oscillations in the region. Likewise, the same method was applied to the squared 6-20-day vorticity for the box area as in Fig. 1a. The result is in Fig. 2b and a regime shift in 1994 was also detected for the squared 6-20-day vorticity. Therefore, the interdecadal variability of the ISO might influence the development of smaller-scale phenomena such as the submonthly wave pattern (Ko et al. 2012). Thus, it is interesting to explore the characteristics of intraseasonal circulation patterns of these two epochs and their impact on higher-frequency phenomena.

After dividing the 32 years into two epochs, Fig. 2c shows the climatological mean flow pattern from July to September of 1979 - 1993 in East Asia and the western North Pacific. A subtropical anticyclone was centered near $30^{\circ} \mathrm{N}$, $160^{\circ} \mathrm{W}$, and a monsoon trough was located from the northern portion of the South China Sea to around $10^{\circ} \mathrm{N}, 145^{\circ} \mathrm{E}$. The OLR minimal areas are located over the southern flank of the trough. In comparison, the mean streamfunction of 1994 - 2010 (Fig. 2d) revealed a subtropical anticyclone that extended westward and was accompanied by a stronger monsoon trough. The OLR minimal area (convection) was enhanced due to strengthened confluence. After subtracting the climatological mean streamfunction of 1979 - 1993 from that of 1994 - 2010 (Fig. 2e), a positive streamfunction anomaly centered near the northern flank of the subtropical anticyclone emerged and positive streamfunction anomalies covered almost all the WNP area. In addition, a secondary anticyclonic anomaly was centered near $15^{\circ} \mathrm{N}, 150^{\circ} \mathrm{E}$ with significant winds over the southwestern and northwestern flanks of it. An anomalous ridge extended from the aforementioned anticyclonic anomaly southwestward to the southern Philippines. Although the streamfunction anomalies were mostly positive in the WNP, a cyclonic anomaly was located over the northern South China Sea and it was accompanied by an anomalous trough that extended eastward through Taiwan to $25^{\circ} \mathrm{N}, 150^{\circ} \mathrm{E}$. In addition, this cyclonic anomaly and anomalous trough were also associated with significant southwesterly anomalies near their southern flank. These streamfunction and significant southwesterly anomalies reflected a La-Niña-like pattern (Mujumdar et al. 2012) in the later epoch. Furthermore, an enhanced monsoon trough was usually associated with a more active ISO cyclonic anomaly (Ko and Hsu 2009).

In order to illustrate the interdecadal variability of the ISO and submonthly signals, 3-month variance maps of 30-80-day zonal wind and 6-20-day vorticity at $850 \mathrm{hPa}$ for those two epochs are shown in Fig. 3. A major variance maximum for the 30-80-day zonal wind emerged near the southern portion of the SCS in the 1979 - 1993 epoch (Fig. 3a), and this area was also located in the box area for selecting the 30-80-day events. This maximal variance area was enhanced in the later epoch (Figs. 3c and e). Likewise, in the earlier epoch, a 6-20-day vorticity variance maximum was detected near the oceanic area between Taiwan and Japan where the case selecting box was co-located (Fig. 3b). This maximal variance area also extended southeastward to $10^{\circ} \mathrm{N}, 140^{\circ} \mathrm{E}$. The vorticity variance maximum expanded in the east-west direction in the later epoch, and the axis of the maximal vorticity variance was slightly shifted westward (Fig. 3d). After subtracting the earlier epochal variance from the later, the difference vorticity variance (Fig. 3f) exhibited two positive maxima straddling the axis of the maximal variance for the earlier epoch. This indicates that not only the vorticity variance was stronger, but also more spatial variability for the occurrence of the 6-20-day disturbances was observed in the later epoch.

In addition to the climatological background flow as in Fig. 2, the intraseasonal background fields by averaging the 30-80-day fields between Day -5 and +5 for those selected submonthly cases are shown in Fig. 4. A cyclonic anomaly in the westerly phase of 1979 - 1993 covered most of the East Asian summer monsoon region and was centered near the oceanic area south of southern China and Taiwan. Conversely, in the easterly phase of 1979 - 1993, an east-west elongated anticyclonic anomaly centered near the northern portion of the South China Sea was observed and apparently the eastern portion of this anticyclonic anomaly was loosely organized. Compared with that in the earlier epoch, the flow pattern in the westerly phase of $1994-2010$ exhibited a stronger and more solid structure with the center shifted eastward to southeast of Taiwan. There were also more significant winds located in the northeastern quadrant of the cyclonic anomaly than its counterpart in the earlier epoch. Likewise, the anticyclonic anomaly in the easterly phase of 1994 - 2010 also yielded a stronger feature than that in 1979 - 1993. Evidently, stronger mean circulation (Fig. 2) and larger variability in the later epoch (Fig. 3) was associated with a larger intraseasonal fluctuation.

The climatological mean flow and intraseasonal background flow were added together to illustrate the combination of these two background states and the results are presented in Fig. 5. Although not shown, the resultant combination of $850 \mathrm{hPa}$ circulation resembles the unfiltered background fields. The combined $850 \mathrm{hPa}$ streamfunction in the westerly phase of 1979 - 1993 exhibited a considerably stronger monsoon trough than that for the climatological mean state as in Fig. 2c. Apparently the enhancement was due to the northward-propagating ISO (Ko and Hsu 2009). Conversely, the monsoon trough weakened in the easterly phase caused by the ISO anticyclonic anomaly. Likewise, the circulation pattern in the westerly phase of the later epoch exhibited an even stronger monsoon trough caused by the ISO effect. A broader but weaker monsoon trough was observed in the easterly phase of 1994 - 2010. 
(a) Var 30-80 day u, 1979-1993

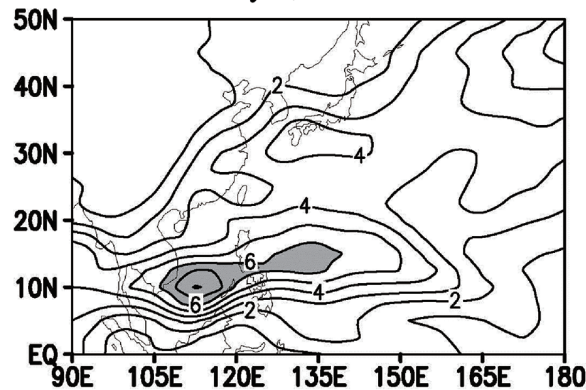

(c) Var 30-80 day u, 1994-2010

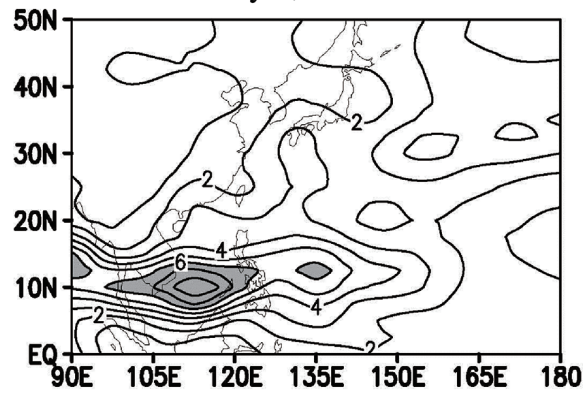

(e) Diff of c and a

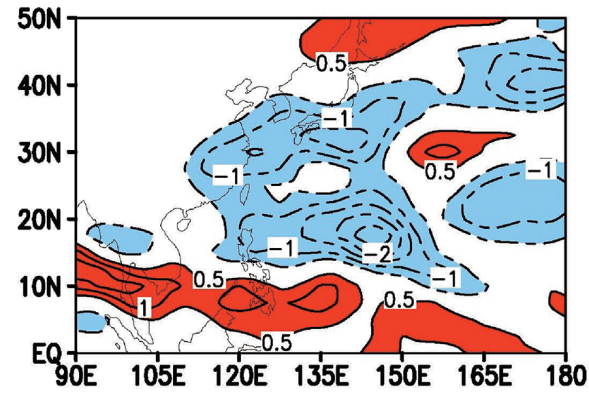

(b) Var 6-20 day vor, 1979-1993

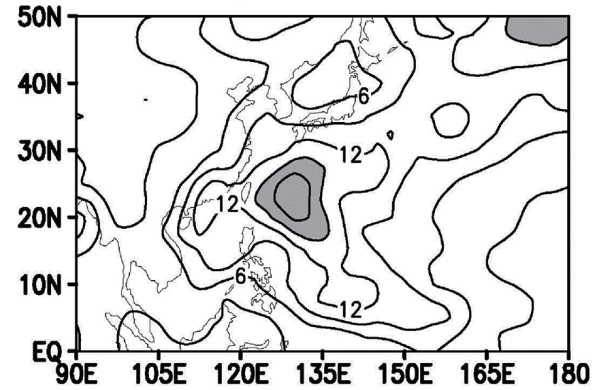

(d) Var 6-20 day vor, 1994-2010

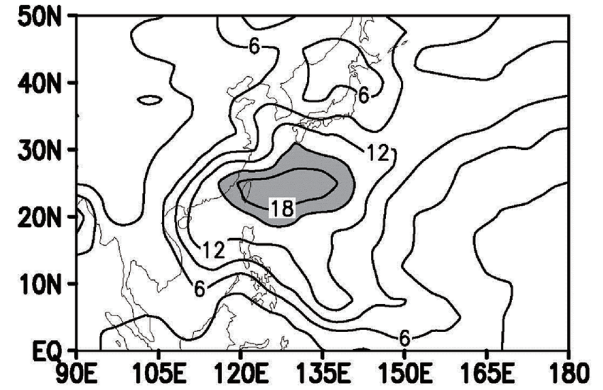

(f) Diff of d and b

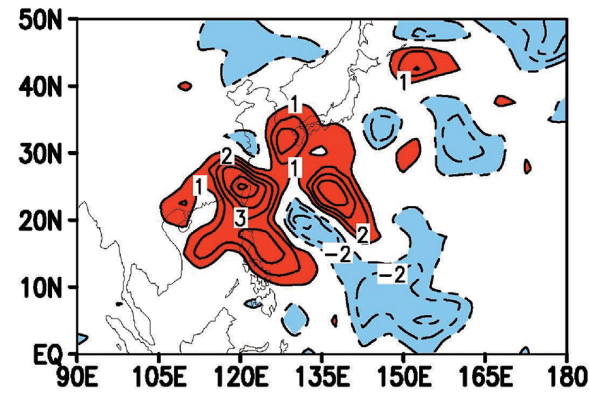

Fig. 3. Variance of 30-80-day zonal wind from July to September for (a) 1979 - 1993 and (c) 1994 - 2010. Panels (b) and (d) are the same except for 6-20-day vorticity. Areas greater than $6 \mathrm{~m}^{2} \mathrm{~s}^{-2}$ in (a) and (c) are shaded, and areas greater than $15 \times 10^{-10} \mathrm{~s}^{-2}$ in (b) and (d) are shaded. The differences between (c) and (a) [(d) and (b)] are shown in (e) [(f)], and areas greater than $0.5 \mathrm{~m}^{2} \mathrm{~s}^{-2}\left(1 \times 10^{-10} \mathrm{~s}^{-2}\right)$ are shaded in red and areas less than $-0.5 \mathrm{~m}^{2} \mathrm{~s}^{-2}$ $\left(-1 \times 10^{-10} \mathrm{~s}^{-2}\right)$ are shaded in blue. The zero contours in (e) and (f) are omitted. 
(a) submISOw, 1979-1993

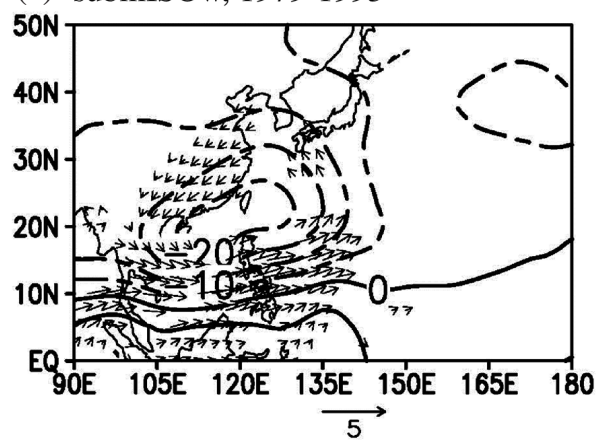

(c) submISOw, 1994-2010

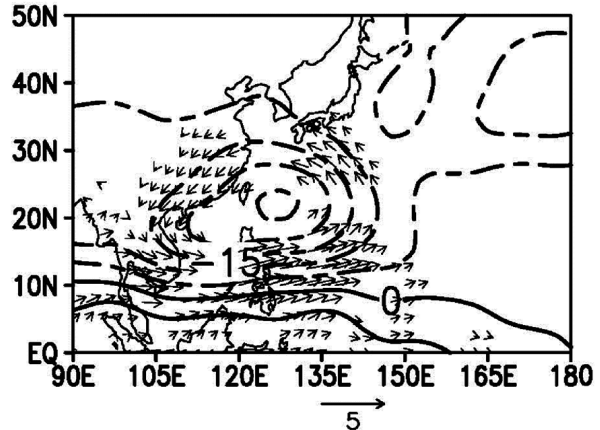

(b) submISOe, 1979-1993

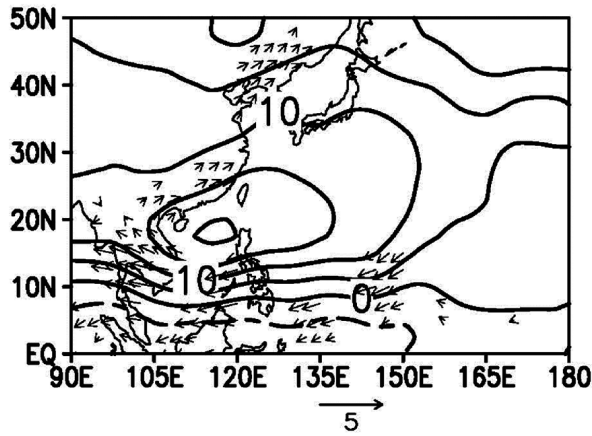

(d) submISOe, 1994-2010

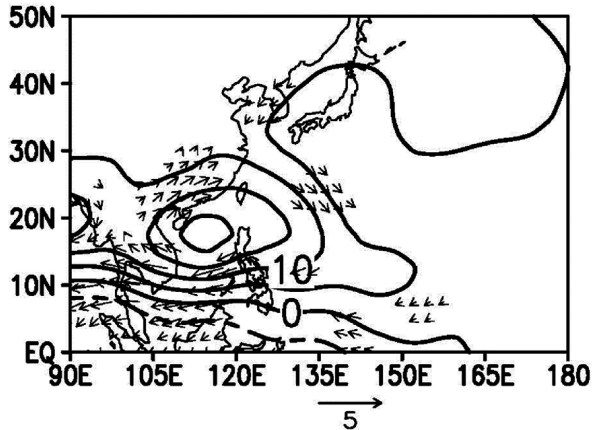

Fig. 4. Mean state maps of 30-80-day filtered $850 \mathrm{hPa}$ streamfunction (thick contours), and winds averaged from Day -5 to +5 during $1979-1993$ for (a) ISO westerly cases, and (b) ISO easterly cases. The mean state maps for $1994-2010$ are shown in (c) and (d), respectively. Only winds exceeding the $95 \%$ confidence level are shown.

(a) C+submISOw, 1979-1993

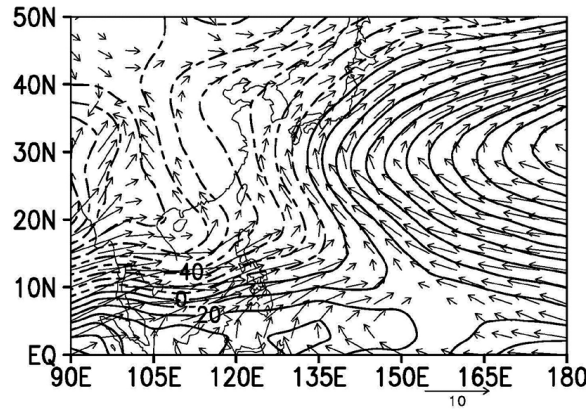

(c) C+submISOw, 1994-2010

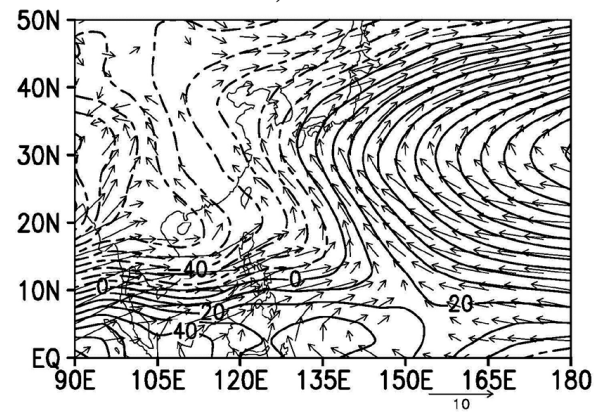

(b) C+submISOe, 1979-1993

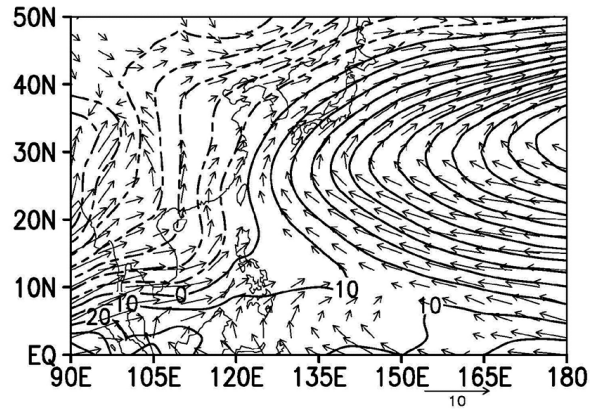

(d) C+submISOe, 1994-2010

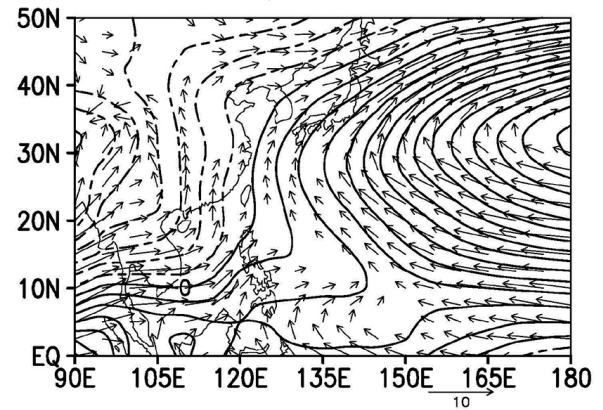

Fig. 5. Mean state maps of climatological mean and 30-80-day filtered $850 \mathrm{hPa}$ streamfunction (contours), and winds averaged from Day -5 to +5 during 1979 - 1993 for (a) ISO westerly cases, and (b) ISO easterly cases. The mean state maps for 1994 - 2010 are shown in (c) and (d), respectively. The contour interval is $10 \times 10^{5} \mathrm{~m}^{2} \mathrm{~s}^{-1}$ for the streamfunction. Winds smaller than $1.5 \mathrm{~m} \mathrm{~s}^{-1}$ are omitted. 


\section{LAG CORRELATION}

The lag-correlation method was applied to link the 6-20-day base region $850 \mathrm{hPa}$ vorticity time series and the 6-20-day filtered $850 \mathrm{hPa}$ streamfunction time series of the other grid points for the selected cases. Figures 6 and 7 show the lag-correlation maps for the two epochs and areas of lag-correlation exceeding the $95 \%$ confidence level are shaded. In the westerly phase of 1979 - 1993, a negative correlation maximum, which could be considered as a cyclonic anomaly, was evident two days before the peak phase in the oceanic area east of Taiwan and it was followed by a positive correlation maximum southeast of it. The negative correlation maximum then intensified and moved slightly northward at the peak phase, and moved farther northward toward Japan two days later. The lag-correlation in the easterly phase of 1979 - 1993, however, exhibited a weaker pattern and smaller significant areas for the major negative correlation maximum. The major negative correlation maxima for both westerly and easterly phases in the later epoch as in Figs. $7 \mathrm{a}$ and $\mathrm{b}$, respectively, revealed more solid patterns and larger significant areas at Lag-2D. These negative correlation maxima continued propagating northwestward toward southeastern China and Taiwan at Lags 0D (Figs. 7c and d) and decayed gradually at Lag $+2 \mathrm{D}$ (Figs. 7e and f). The directions of propagation for the negative correlation maxima in the later epoch yielded a stronger and farther westward tendency than their counterparts as in the earlier epoch. Overall, the correlation signals in 1994 - 2010 were more enhanced at Lags $-2 \mathrm{D}$ and $0 \mathrm{D}$ and the wave pattern tended to move farther west into the land, indicating a better organized structure and farther westward propagating tendency in the later epoch.

After plotting the tracks of the centers for the major negative correlation maxima (cyclonic anomalies) between Lag $-4 \mathrm{D}$ and $+2 \mathrm{D}$, Fig. 8 showed that the tracks in the westerly phases of both epochs were similar before Lag 0D (crosses), but they diverged to separate directions approximately after Lag 0D. The phase speed before Lag 0D was slower in the later epoch. The center of the cyclonic anomaly tended to move farther northward in 1979 - 1993, whereas in the later epoch, it would propagate faster and farther westward toward eastern China. Likewise, similar contrast of tracks in the easterly phase between two epochs was also evident except they were originated from farther east. The propagation pattern in the easterly phase usually dominated by the background flow (Ko and Hsu 2009). The track of the cyclonic anomaly center in 1979 - 1993 came from an area farther east because the background monsoon trough extended farther eastward (Fig. 5). The TC track patterns in both phases and epochs also supported a further northward propagating tendency existed in 1979 - 1993, whereas further westward propagating patterns were observed in the later epoch. It is suggested that the enhanced climatological easterly over the area between Taiwan and Japan as in Fig. 2e in the later epoch could be responsible for the aforementioned further westward track patterns. It is also noted in Fig. 2e that an enhanced cyclonic anomaly centered near southern China and extending eastward to $25^{\circ} \mathrm{N}, 150^{\circ} \mathrm{E}$, would also attract the submonthly cyclonic anomalies and the associated TCs to move westward. Therefore, the propagating tendency of the cyclonic anomalies and TCs tended to move northward and would bring damage to areas over Japan in the earlier epoch, whereas they would be more likely to hit Taiwan and eastern China in the later epoch.

\section{KINETIC ENERGY AND BAROTROPIC INTERACTIONS}

To demonstrate the interdecadal variability of the submonthly kinetic energy, the 6-20-day perturbation kinetic energy (PKE) at $850 \mathrm{hPa}$ averaged between Day -5 and +5 for the submonthly cases in those two epochs is shown in Fig. 9. In the westerly phase of 1979 - 1993, a PKE maximum was centered near the area between Taiwan and southern Japan. The axis of the PKE maximum extended southeastward to the equatorial West Pacific. The easterly phase, however, exhibited a much weaker maximum. This contrast is consistent with the finding in Ko et al. (2012) that the stronger monsoon trough during the ISO westerly phase provided more energy converted to the submonthly perturbations. Compared with the patterns for the former epoch, the PKE maxima in the westerly and easterly phases of 1994 - 2010 were considerably stronger and the areas were larger. After subtracting the PKE of 1979 - 1993 from that of 1994 - 2010, the difference maps yielded maximal areas mostly in the eastern and southeastern portions of the PKE maxima. This may imply the interdecadal variability enhances the submonthly PKE from the upstream area of the wave pattern.

Because one of the objectives for the current study is to investigate the interactions between the background flow and submonthly perturbations, the barotropic conversion (kp) term in the kinetic energy equation [Eq. (1)] is examined using different background flow patterns. The background flow patterns are organized as the climatological mean (July-to-September mean, denoted as Clim), intraseasonal, and the combination of the two (Clim+ISO).

\subsection{Effect of Interdecadal Mean State Changes}

In order to assess the contribution by the climatological mean background flow, the kp term was calculated using the submonthly perturbations and the climatological mean fields only and the results are shown in Figs. 10a and c. A sensitivity test on the background flow was performed by switching the climatological background flow of those two epochs. The sensitivity of the kp term was further examined 
(a) Lag -2D, westerly, 1979-1993

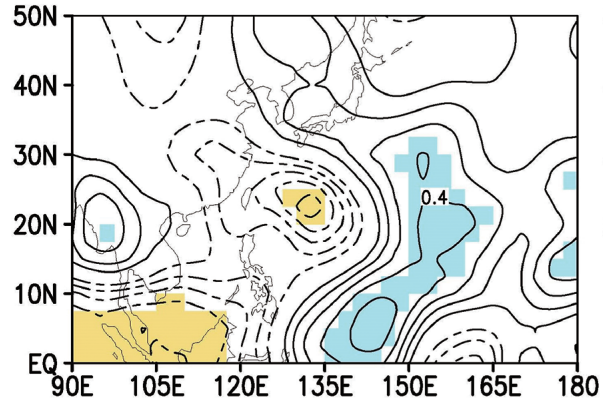

(c) Lag 0D, westerly, 1979-1993

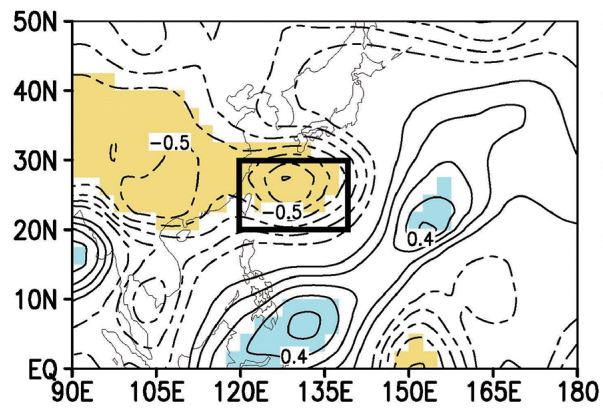

(e) Lag +2D, westerly, 1979-1993

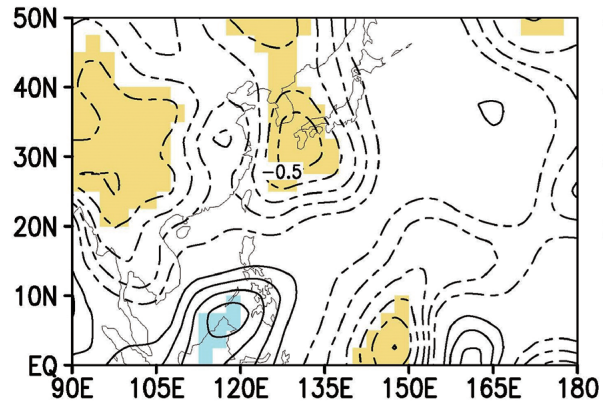

(b) Lag -2D, easterly, 1979-1993

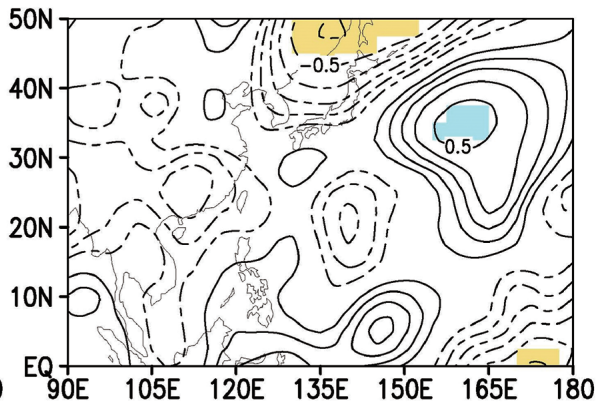

(d) Lag 0D, easterly, 1979-1993

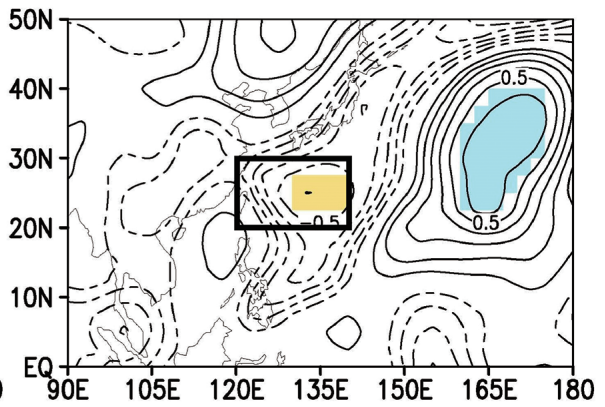

(f) Lag +2D, easterly, 1979-1993

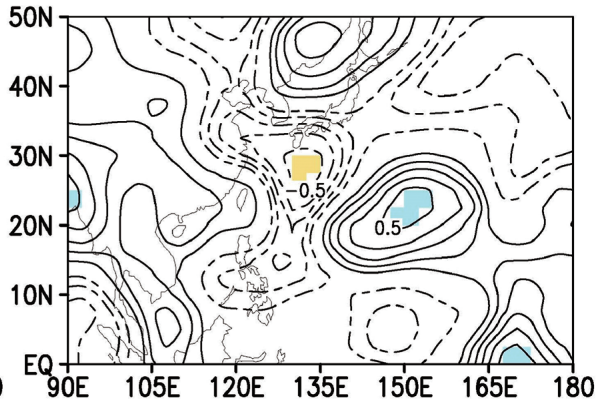

Fig. 6. Lag-correlation between the base region 6-20-day vorticity and 6-20-day streamfunction at $850 \mathrm{hPa}$ during 1979 - 1993 for ISO westerly cases at (a) Lag-2D, (c) Lag 0D, and (e) Lag+2D, and for ISO easterly cases at (b) Lag-2D, (d) Lag 0D, and (f) Lag+2D. The contour interval is 0.1 and the zero contours are omitted. Areas exceeding the $90 \%$ confidence level are shaded in blue (positive) and yellow (negative). The thick black boxes at Lag $0 \mathrm{D}$ represent the base regions. 
(a) Lag -2D, westerly, 1994-2010

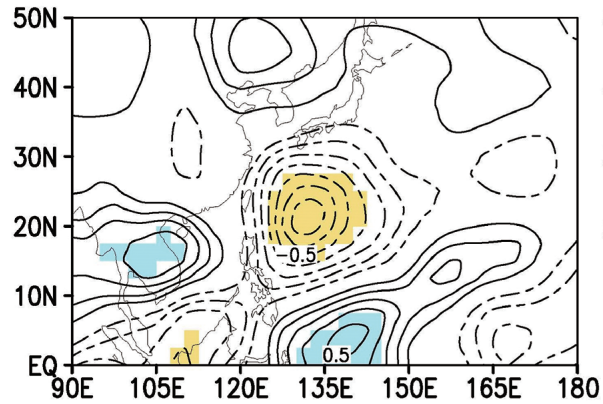

(c) Lag 0D, westerly, 1994-2010

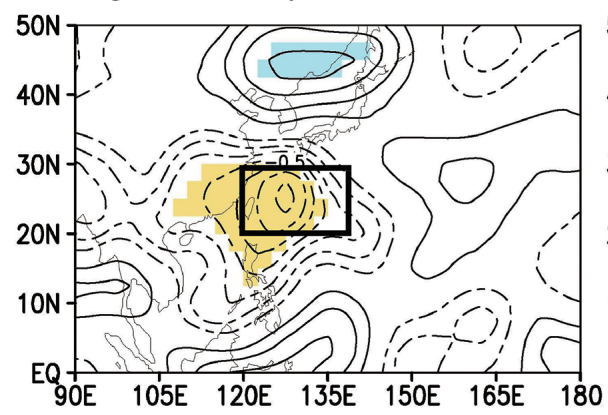

(e) Lag +2D, westerly, 1994-2010

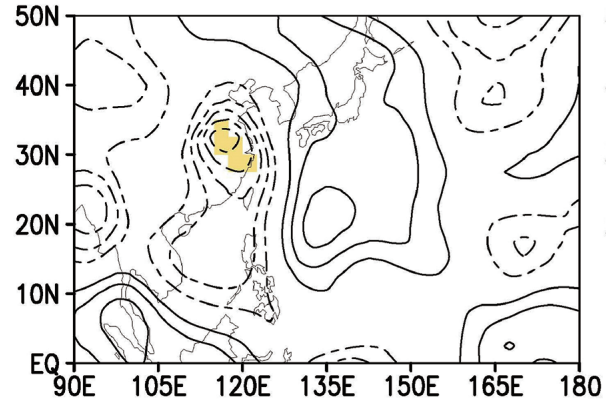

(b) Lag -2D, easterly, 1994-2010

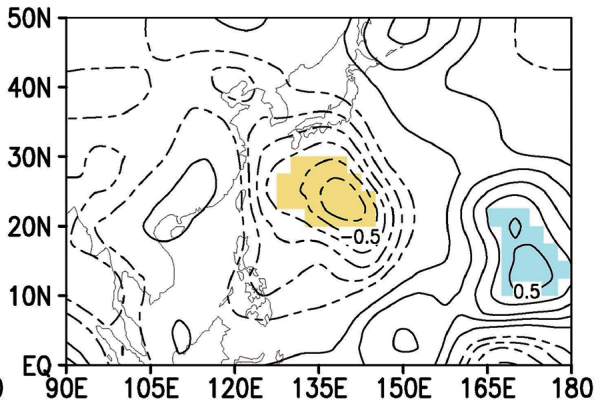

(d) Lag 0D, easterly, 1994-2010

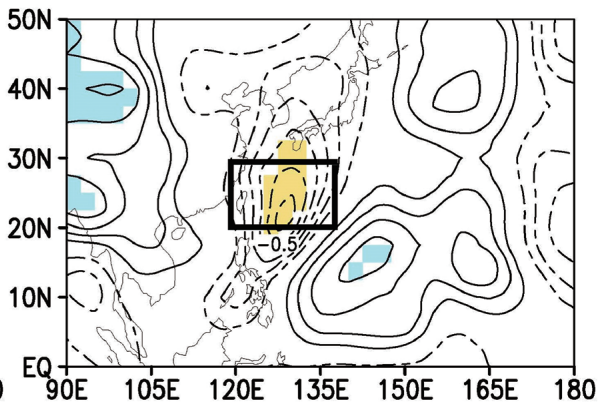

(f) Lag +2D, easterly, 1994-2010

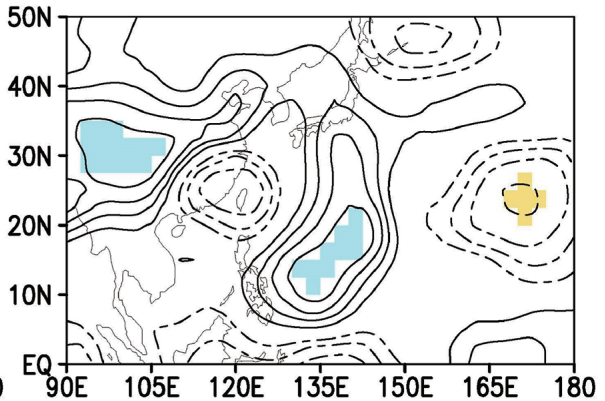

Fig. 7. Same as Fig. 6 except for 1994 - 2010.

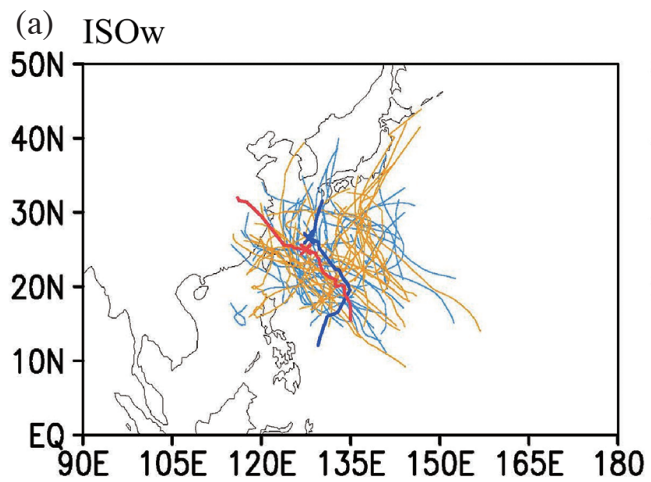

(b) ISOe

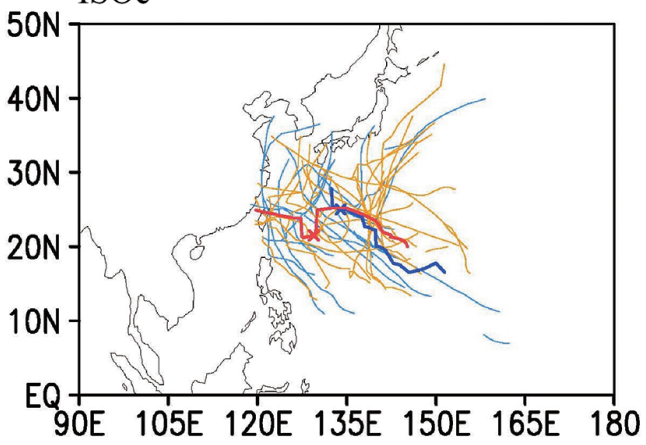

Fig. 8. Tracks of the major lag-correlation negative maxima between the base region 6-20-day vorticity and 6-20-day 850 hPa streamfunction from Lag -4D to +2D for (a) ISO westerly cases, and (b) ISO easterly cases. The thick blue lines stand for the tracks for the 1979 - 1993 yrs and thick red lines are for the $1994-2010$ yrs, respectively. The crosses represent the positions at Lag 0D. Also shown are the corresponding TC tracks (thin light blue lines for 1979 - 1993 and thin yellow lines for 1994 - 2010, respectively). 
(a) Westerly, 1979-1993

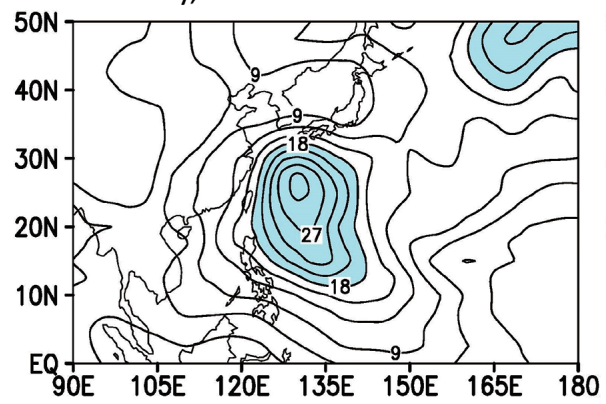

(c) Westerly, 1994-2010

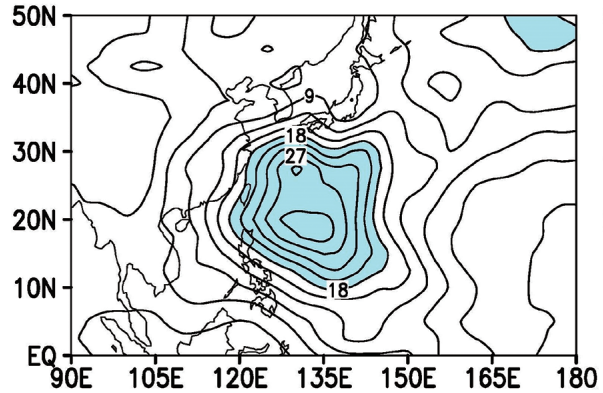

(e) Westerly 9410-7993

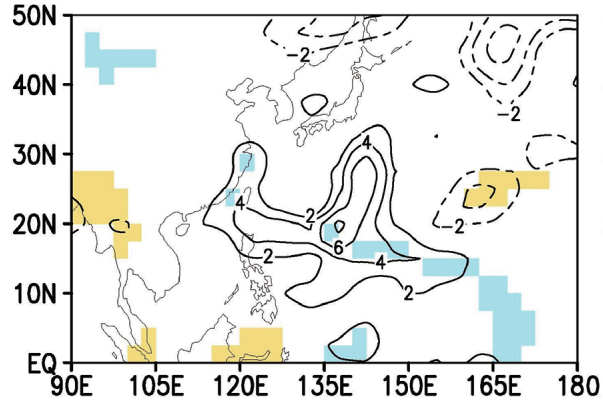

(b) Easterly, 1979-1993

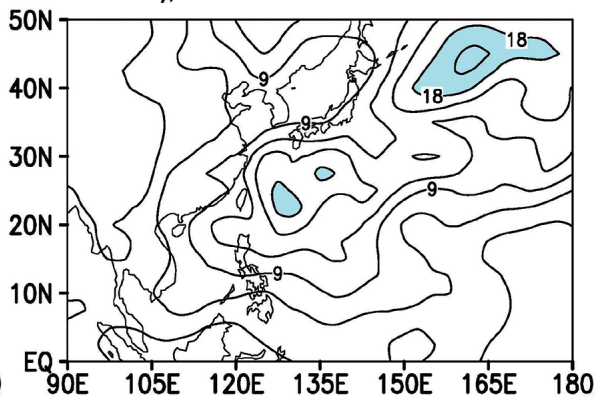

(d) Easterly, 1994-2010

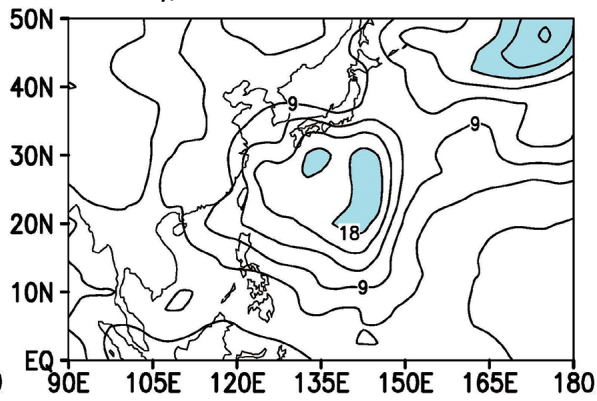

(f) Easterly 9410-7993

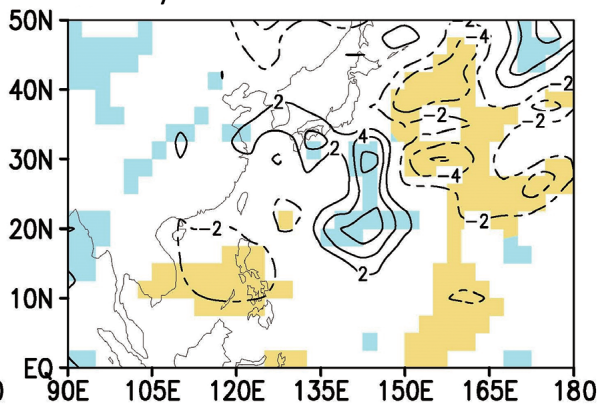

Fig. 9. Perturbation kinetic energy (PKE) of the 6-20-day filtered winds averaged from Day -5 to +5 for (a) westerly phase, 1979 - 1993, (b) easterly phase, 1979 - 1993, (c) westerly phase, 1994 - 2010, and (d) easterly phase, $1994-2010$. PKE greater than $18 \mathrm{~m}^{2} \mathrm{~s}^{-2}$ is shaded in blue. Also shown are the PKE difference maps for (e) westerly and (f) easterly phases. Only areas exceeding the $95 \%$ confidence levels are shaded for (e) and (f). The zero contours are omitted. 
(a) Westerly, 1979-1993

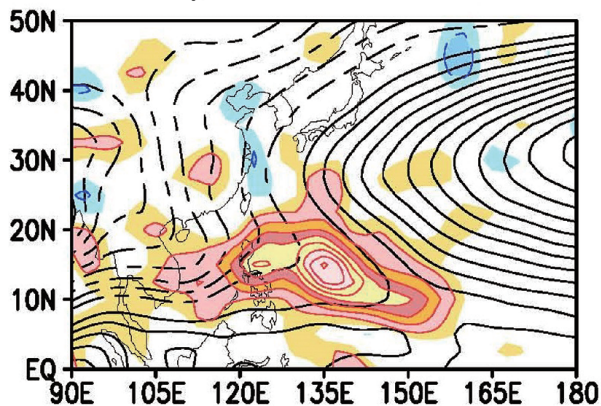

(c) Westerly, 1994-2010

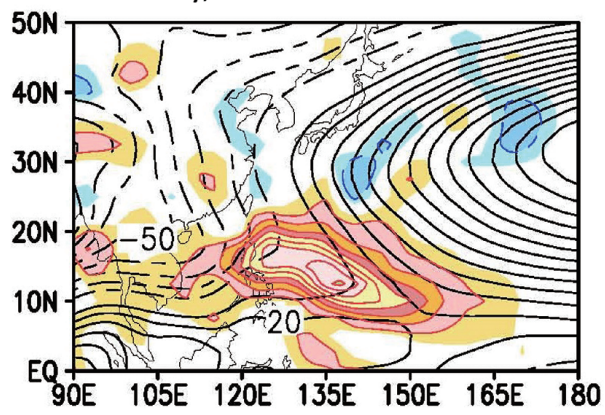

(b) Westerly, 1979-1993 switched

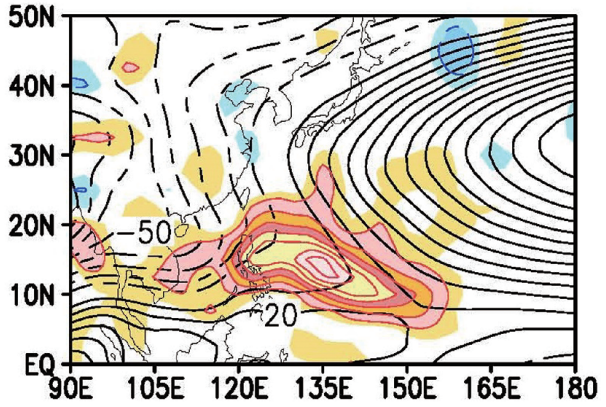

(d) Westerly, 1994-2010 switched

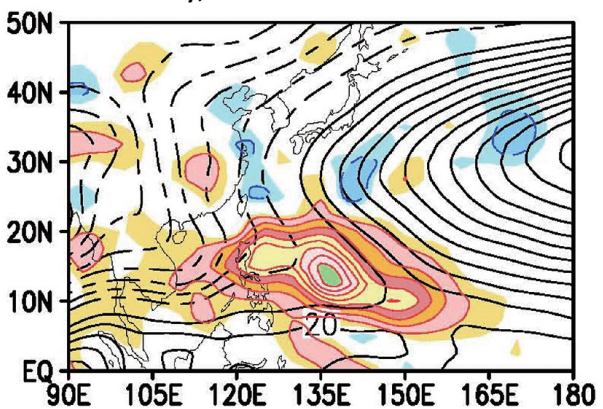

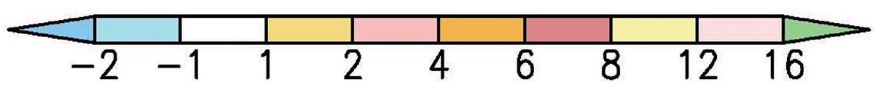

(e) Diff

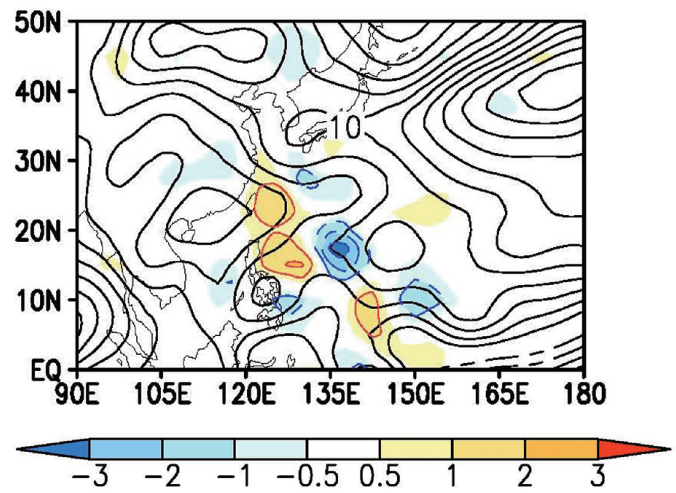

Fig. 10. Barotropic conversion term $\left(10^{-5} \mathrm{~m}^{2} \mathrm{~s}^{-3}\right.$, shaded) and the mean streamfunction (contour interval is $\left.10 \times 10^{5} \mathrm{~m}^{2} \mathrm{~s}^{-1}\right)$ at $850 \mathrm{hPa}$ computed from Day -5 to +5 between the 6-20-day filtered and climatological mean July-to-September fields in the ISO westerly cases for (a) 1979 - 1993 , and (c) 1994 - 2010. The panels in (b) and (d) are the same except the background fields are switched. Also shown in (e) is the difference map of the barotropic conversion term $\left(10^{-5} \mathrm{~m}^{2} \mathrm{~s}^{-3}\right.$, shaded) mean streamfunction (contour) between the one as in (b) and (a). 
by switching the climatological background states between these two epochs. After replacing the background field by the later epochal one, the $\mathrm{kp}$ areas in the westerly phase of 1979 - 1993 shrank over the eastern portions, but enhanced in the western maximal area. Note that the kp terms in 1979 - 1993 and 1994 - 2010 but calculated based on 1994 - 2010 background flow exhibits similar distributions (Figs. 10b and c). The similarity is also found in the calculation based on 1979 - 1993 background flow (Figs. 10a and d). This result suggests the dominance of background field in affecting energy conversion.

The difference in the westerly phase was more evident after subtracting the $\mathrm{kp}$ terms and streamfunction for the switched background fields (Figs. 10b and d) from that for the unswitched background fields (Figs. 10a and c). Only the difference for 1979 - 1993 (Fig. 10e) is shown because the pattern is similar but reversed to that in the later epoch. The resultant difference shows that in the northeastern and eastern flanks of the major $\mathrm{kp}$ areas, the $\mathrm{kp}$ terms decreased but they strengthened in the western and southern flanks after replacing the 1994 - 2010 background fields in calculating the 1979 - $1993 \mathrm{kp}$ terms. This pattern change could be due to the enhanced easterly anomalies generated by the later epochal secondary anticyclonic anomaly near $20^{\circ} \mathrm{N}, 150^{\circ} \mathrm{E}$ and this circulation change would modify the distribution of the background easterly flow near the major $\mathrm{kp}$ areas so that the major $\mathrm{kp}$ areas could be displaced farther westward. Therefore, changing the background flow can have an impact on the kp term.

\subsection{Contribution of ISO Background Interdecadal Changes}

To demonstrate the sensitivity of the background contribution by the ISO to the kp terms, the background fields in the westerly phases were replaced by the intraseasonal mean kinematic fields and the results are presented in Figs. 11a and c. A solid positive kp area was observed in the southeastern quadrant of the ISO cyclonic anomaly in the westerly phase of 1979 - 1993. These kp patterns agree with the findings in Ko and Hsu (2014). In the later epoch, the positive $\mathrm{kp}$ area was larger and extended farther eastward to $160^{\circ} \mathrm{E}$ in the westerly phase. The enhancement and eastward-extending tendency in the westerly phase of the later epoch agree with the findings by Kajikawa et al. (2009). After replacing the ISO background fields by the later epochal fields (Figs. 11b and d), the kp term in the westerly phase of 1979 - 1993 became stronger and extended farther eastward. On the other hand, the kp term in the westerly phase of the later epoch became weaker after replacing the background ISO fields. Interestingly, the kp patterns switch when the intraseasonal background flows switch. It follows that the background ISO fields dictated the intensity and shapes in energy conversion $\mathrm{kp}$ terms.
After subtracting the stremfunction and kp terms in the westerly phases of the switched background ISO fields as in Figs. $11 \mathrm{~b}$ and $\mathrm{d}$ from that of the unswitched background ISO fields in Figs. 11a and c, a positive kp difference area was located in the southern flank of the difference ISO cyclonic anomaly in the westerly phase of 1979 - 1993, indicating that the background ISO westerly field of the later epoch favored the strengthening of the ISO cyclonic anomaly and the $\mathrm{kp}$ term. It is also noted that the easterly anomalies near the northern flank of the difference ISO cyclonic anomaly would help the corresponding TC/submonthly wave move farther westward as in Fig. 8a. Moreover, the easterly anomalies were also collocated with the difference easterly anomalies in the northern flank of the enhanced monsoon trough in the later epoch as in Fig. 2e. Although the positive $\mathrm{kp}$ difference areas were weaker than and located near the positive kp differences calculated by using the climatological background flow as in Fig. 10e, they favored the interaction between the background ISO field and westwardshifted TC/submonthly wave patterns. This might suggest the interdecadally varying ISO modulating effect played a supporting role in enhancing the $\mathrm{kp}$ terms as the climatological background flow did and they both steered the TC/ submonthly wave patterns farther westward. In other words, the climatological background flow in the later epoch would strengthen the monsoon trough and favor the ISO in order to intensify the $\mathrm{kp}$ terms in the western portion of the maximal $\mathrm{kp}$ area. However, the anticyclonic anomaly generated by the later epochal climatological background flow could also decrease the $\mathrm{kp}$ terms in the eastern portion $\left(10^{\circ} \mathrm{N}, 150^{\circ} \mathrm{E}\right)$. After adding the climatological and ISO background flows together, the difference kp map (Fig. 11f) showed that the enhancement in the western portion was even stronger, indicating the aforementioned enhanced interaction between the background flow and TC/submonthly wave patterns.

\subsection{Contribution of Background Fields on the Barotropic Conversion}

The barotropic interaction was further studied by analyzing the individual terms on the right hand side of Eq. (1). Although the first two terms are the dominant terms (Ko et al. 2012), the first term is considerably larger than the second one. Therefore the first term on the right hand side of Eq. (1) is separated into two components: $\overline{\mathrm{u}^{\prime 2}}$ and $\frac{\partial \overline{\mathrm{u}}}{\partial \mathrm{x}}$, and the results for the westerly phases using the climatological mean background fields are presented in Figs. 12a and c. In the westerly phase of $1979-1993$, a $\overline{u^{\prime 2}}$ maximum was centered just south of southern Japan and the maximal area extended southeastward to $10^{\circ} \mathrm{N}, 160^{\circ} \mathrm{E}$. The background component $\left(\frac{\partial \overline{\mathrm{u}}}{\partial \mathrm{x}}\right)$ negative maximal areas were located in the southern and southeastern flanks of the $\overline{u^{\prime 2}}$ maximum. Compared with that in the earlier epoch, the perturbation component in the westerly phase of 1994 - 2010 was larger 
(a) Westerly, 1979-1993

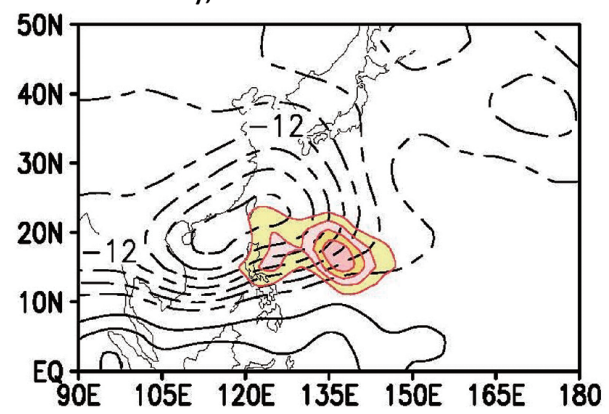

(c) Westerly, 1994-2010
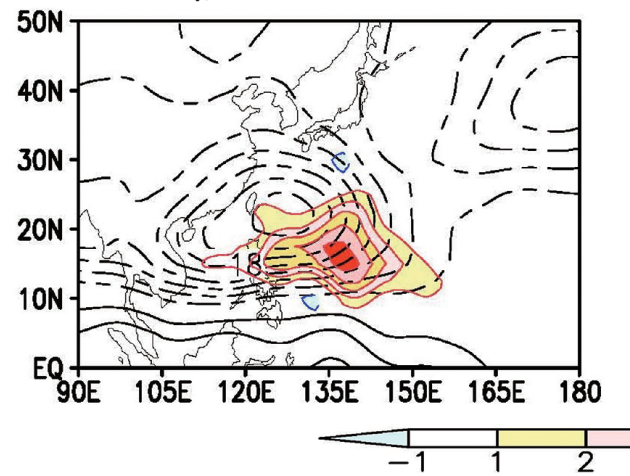

(e) Diff

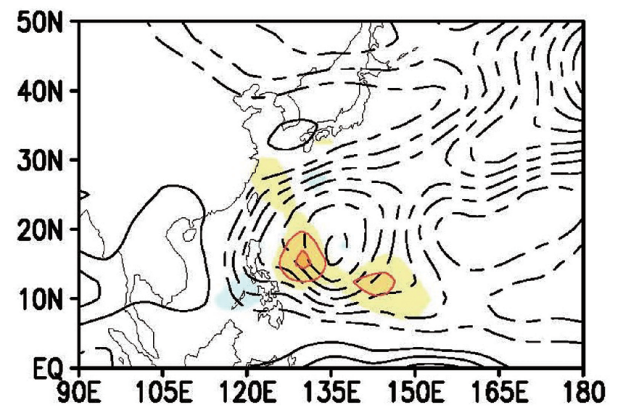

(b) Westerly, 1979-1993 switched

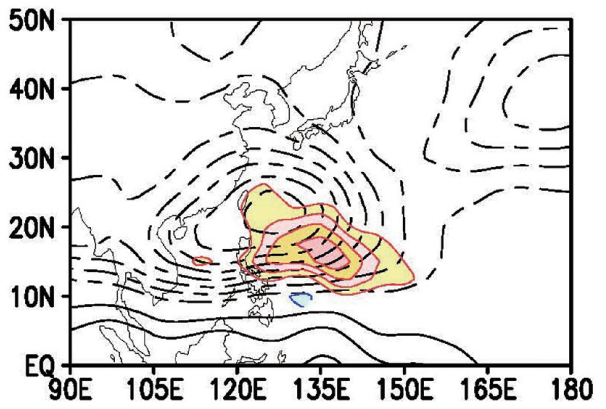

(d) Westerly, 1994-2010 switched

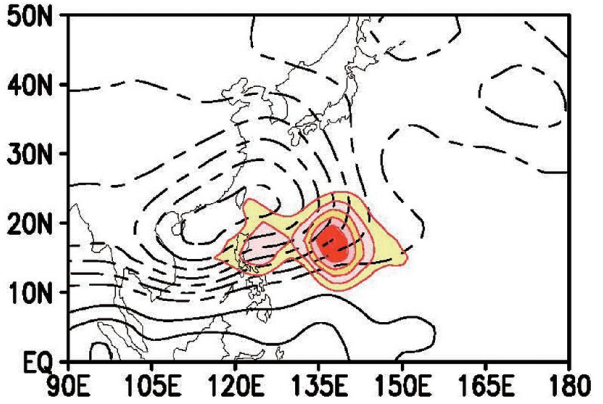

(f) $\operatorname{Diff}(\mathrm{Cx}+\mathrm{ISO}$-C-ISO)

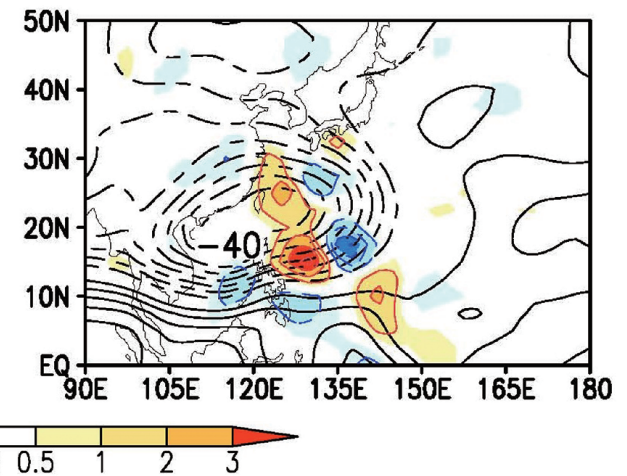

Fig. 11. Same as Figs. 10a - e except for the 30-80-day background states. The difference of the streamfunction (black contour) and barotropic conversion between the 6-20-day filtered and climatological mean July-to-September +30 -80-day filtered mean (switched-unswitched) is in (f). 
(a) Westerly, 1979-1993

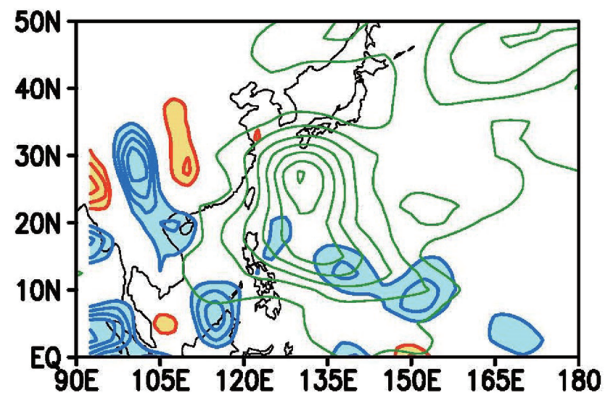

(c) Westerly, 1994-2010

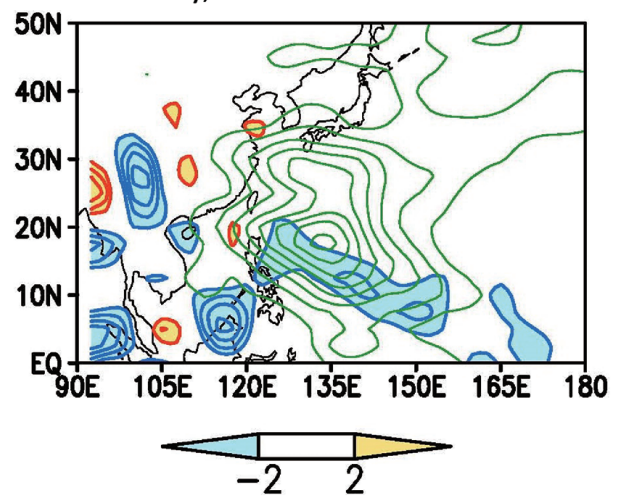

(b) ISO westerly, 1979-1993

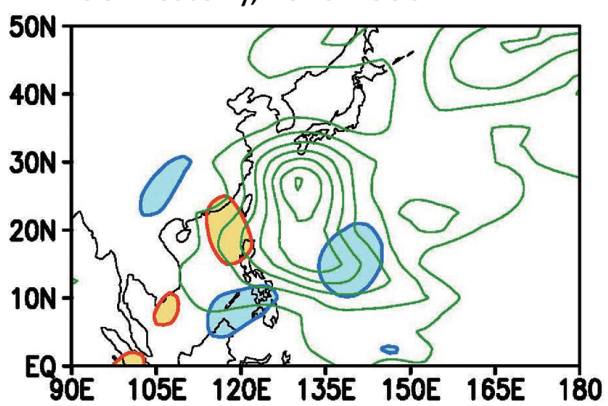

(d) ISO westerly, 1994-2010

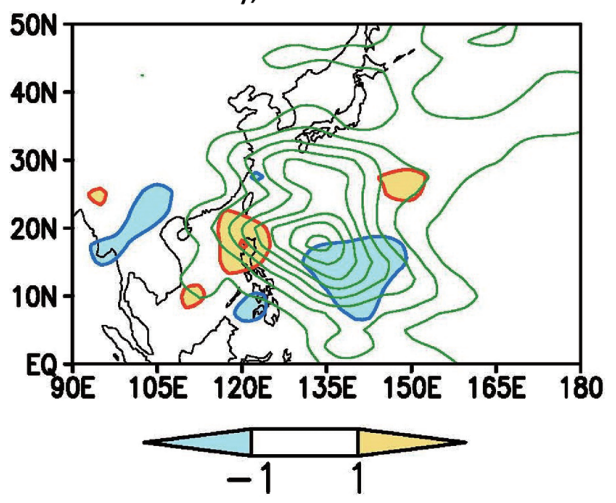

Fig. 12. Perturbation components of the dominant term for the barotropic conversion term ( $\overline{\mathrm{u}^{\prime 2}}$, green contour) at $850 \mathrm{hPa}$ computed from Day -5 to +5 for the 6-20-day filtered fields in the unfiltered ISO westerly cases for (a) $1979-1993$, (c) $1994-2010$. The contour interval is $5 \mathrm{~m}^{2} \mathrm{~s}^{-2}$ for the $\overline{\mathrm{u}^{\prime 2}}$ and only values $\geq 10 \mathrm{~m}^{2} \mathrm{~s}^{-2}$ are shown. Also shown is the $\frac{\partial \overline{\mathrm{u}}}{\partial \mathrm{x}}$ term for the climatological fields (shaded) and the contour interval is $10^{-6} \mathrm{~s}^{-1}$. The same components except the background fields are replaced by the 30-80-day filtered fields are shown in (b) and (d).

and centered south of that as its counterpart of the earlier epoch. This is also consistent with the PKE increase over the eastern and southeastern portions of the PKE maximum as in Fig. 9e. The background component was stronger and its axis was situated slightly west of that for the earlier epoch. The western portion of the $\frac{\partial \overline{\mathrm{u}}}{\partial \mathrm{x}}$ negative maximum was co-located with the maximal perturbation component. This comparison explains why the kp term is stronger and larger in spatial domain in 1994 - 2010 epoch.

Further studies on the dominant term for the barotropic conversion in the westerly phases were performed using the ISO background components (Figs. 12b and d). The negative $\frac{\partial \overline{\mathrm{u}}}{\partial \mathrm{x}} \frac{\mathrm{maximal}}{\mathrm{u}^{2}}$ area located near the southeastern quadrant of the $\overline{\mathrm{u}^{\prime 2}}$ maximal area was larger and expanded further west in the later epoch. Therefore, the relative positions of $\overline{\mathrm{u}^{\prime 2}}$ and $\frac{\partial \overline{\mathrm{u}}}{\partial \mathrm{x}}$ reveal why the positive $\mathrm{kp}$ was located in the southeastern quadrant of the ISO perturbation and why the $\mathrm{kp}$ was larger in the later epoch. Overall, the ISO background components showed a westward enhancement of the background fields and thus favored the westward propagating tendency of the TC/submonthly wave patterns.

\section{SUMMARY AND DISCUSSION}

The interdecadal variability of the northward-propagating ISO modulating effect on the submonthly wave patterns in the WNP was investigated by separating the 32 years into 1979 - 1993 and 1994 - 2010 following the regime shift indices occurring in 1994 for both squared 30-80-day zonal wind near the northern SCS and squared 6-20-day vorticity over the base region for the submonthly cases. The variance maps of the 30-80-day zonal wind and 6-20-day vorticity both yielded stronger patterns in the later epoch. Besides, the mean circulation differences from July to September between two epochs yielded an enhancement of the monsoon trough and the strengthened subtropical anticyclone in 1994 $-2010$.

Cases were selected for the submonthly wave patterns and they were further categorized into the ISO westerly and easterly phases for both epochs. The lag-correlation results indicate that the propagation routes of the submonthly perturbations diverged for the two epochs: they tended to move northward to Japan and the phase speed decreased after the 
peak phase in 1979 - 1993 whereas they would propagate farther westward and faster in the later epoch. It is suggested that this decadal circulation change in enhancing the subtropical anticyclone would strengthen the easterly background flow and steer the submonthly perturbations to move further westward to eastern China in the later epoch. These diverse patterns of the propagation routes for the two epochs could be useful in assessing the climate impact or damage for the aforementioned areas in East Asia.

In examining the kinetic energy for those two epochs, the submonthly PKE in 1994 - 2010 exhibited a larger maximal area and significant increase in the eastern and southeastern flanks of the maximal PKE area. This finding suggests that the submonthly wave pattern in the later epoch developed rapidly in the earlier stage before reaching the peak phases.

The interdecadal variability of circulation changes and interactions between background states and TC/submonthly wave patterns were further investigated using the barotropic interaction techniques used by Ko et al. (2012) and Ko and Hsu (2014). The background states were divided into two: climatological 3-month (July to September) mean and ISO mean. The kp terms calculated by the submonthly perturbations and individual climatological mean fields for each epoch showed maximal areas over the monsoon trough in the westerly phase. A sensitivity test was conducted by switching the climatological mean fields of those two epochs and the results show that the later epochal mean field would strengthen the $\mathrm{kp}$ terms in the western and southern portions of the kp maximal areas but weaken them in the eastern and northern portions of the $\mathrm{kp}$ maxima. This westward change of the kp maxima could be caused by the enhanced easterly anomalies in 1994 - 2010.

After replacing the background flow by the ISO mean fields, the kp maxima in the westerly phases were enhanced and extended farther east in the later epoch. This could be accounted for by a strengthened intraseasonal cyclonic anomaly associated with more energetic ISO background flow in the later epoch. Therefore, the change in the ISO westerly background flow due to the interdecadal variability considerably strengthened the ISO cyclonic anomaly and enhanced the energy conversion from the ISO to submonthly perturbations. Interestingly, the enhancement of the $\mathrm{kp}$ terms due to the interdecadally varying ISO, though weaker, was collocated with that by the climatological background circulation changes near the western portion of the kp maximal area where more TCs were detected and propagated farther westward. Therefore, the ISO modulating effect under the interdecadal variability acts as supporting the effect by climatological background flow in enhancing the barotropic conversion and favoring the development of the wave patterns and TCs in the later epoch.

The aforementioned results indicate that the effect on interdecadal variability of the climatological mean fields exceeded the ISO effect. Overall speaking, the mean flow changes around 1993 - 1994 enhanced both intraseasonal and TC-submonthly perturbations in the WNP by providing more kinetic energy. And, the enhanced intraseasonal variability further amplified the conversion of kinetic energy from the background flow to the perturbations. In other words, the multiscale interaction in the WNP was intensified after 1993/1994. Although the present study chose cases with TCs, the roles of TCs on the interdecadadal background circulation changes remained unknown. Hsu et al. (2008) showed that TCs contributed more than $50 \%$ in certain regions to the seasonal mean and ISO. A study using a new dataset with TCs removed is planned to uncover this important issue on the interdecadal changes.

Acknowledgements The authors thank NCEP for the circulation data and NOAA for the OLR data. This study was conducted when the first author (K.-C. Ko) was on sabbatical leave to visit Research Center for Environmental Changes, Academia Sinica. Partial support from Academia Sinica is also acknowledged. Comments from two anonymous reviewers improved the quality of this paper and the authors thanked them for their suggestion. This study was supported by the Ministry of Science and Technology, Taiwan (Grant MOST 106-2111-M-017-001 issued to Dr. Ken-Chung Ko and Grant MOST 106-2111-M-002-013 issued to HuangHsiung Hsu).

\section{REFERENCES}

Chang, C.-P., J. M. Chen, P. A. Harr, and L. E. Carr, 1996: Northwestward-propagating wave patterns over the tropical western North Pacific during summer. Mon. Weather Rev., 124, 2245-2266, doi: 10.1175/1520-0493(1996)124<2245:npwpot>2.0. co;2. [Link]

Chen, J.-M. and H.-S. Chen, 2011: Interdecadal Variability of summer rainfall in Taiwan associated with tropical cyclones and monsoon. J. Clim., 24, 5786-5798, doi: 10.1175/2011jcli4043.1. [Link]

Hsu, H.-H. and C.-H. Weng, 2001: Northwestward propagation of the intraseasonal oscillation in the western North Pacific during the boreal summer: Structure and mechanism. J. Clim., 14, 3834-3850, doi: 10.1175/1520-0442(2001)014<3834:npotio>2.0.co;2. [Link]

Hsu, H.-H., C.-H. Hung, A.-K. Lo, C.-C. Wu, and C.W. Hung, 2008: Influence of tropical cyclones on the estimation of climate variability in the tropical western North Pacific. J. Clim., 21, 2960-2975, doi: 10.1175/2007jcli1847.1. [Link]

Kajikawa, Y. and B. Wang, 2012: Interdecadal change of the South China Sea summer monsoon onset. J. Clim., 25, 3207-3218, doi: 10.1175/JCLI-D-11-00207.1. [Link] 
Kajikawa, Y., T. Yasunari, and B. Wang, 2009: Decadal change in intraseasonal variability over the South China Sea. Geophys. Res. Lett., 36, L06810, doi: 10.1029/2009GL037174. [Link]

Kalnay, E., M. Kanamitsu, R. Kistler, W. Collins, D. Deaven, L. Gandin, M. Iredell, S. Saha, G. White, J. Woollen, Y. Zhu, M. Chelliah, W. Ebisuzaki, W. Higgins, J. Janowiak, K. C. Mo, C. Ropelewski, J. Wang, A. Leetmaa, R. Reynolds, R. Jenne, and D. Joseph, 1996: The NCEP/NCAR 40-year reanalysis project. Bull. Amer. Meteorol. Soc., 77, 437-472, doi: 10.1175/1520-0477(1996)077<0437:TNYRP>2.0. $\mathrm{CO} ; 2$. [Link]

Ko, K.-C. and H.-H. Hsu, 2006: Sub-monthly circulation features associated with tropical cyclone tracks over the East Asian monsoon area during July-August season. J. Meteorol. Soc. Jpn., 84, 871-889, doi: 10.2151/ jmsj.84.871. [Link]

Ko, K.-C. and H.-H. Hsu, 2009: ISO Modulation on the Submonthly Wave Pattern and Recurving Tropical Cyclones in the Tropical Western North Pacific. J. Clim., 22, 582-599, doi: 10.1175/2008jcli2282.1. [Link]

Ko, K.-C. and H.-H. Hsu, 2014: Barotropic interactions between summertime tropical cyclones/sub-monthly wave patterns and intraseasonal oscillations over the western North Pacific. Terr. Atmos. Ocean. Sci., 25, 719-726, doi: 10.3319/TAO.2014.04.17.01(A). [Link]

Ko, K.-C., H.-H. Hsu, and C. Chou, 2012: Propagation and maintenance mechanism of the TC/submonthly wave pattern and TC feedback in the western North Pacific. J. Clim., 25, 8591-8610, doi: 10.1175/jcli- d-11-00643.1. [Link]

Kwon, M., J.-G. Jhun, and K.-J. Ha, 2007: Decadal change in east Asian summer monsoon circulation in the mid-1990s. Geophys. Res. Lett., 34, L21706, doi: 10.1029/2007GL031977. [Link]

Lau,K.-H. and N.-C.Lau, 1990: Observed structure and propagation characteristics of tropical summertime synoptic scale disturbances. Mon. Weather Rev., 118, 18881913, doi: 10.1175/1520-0493(1990)118<1888:osapc o>2.0.co;2. [Link]

Lo, T.-T. and H.-H. Hsu, 2008: The early 1950s regime shift in temperature in Taiwan and East Asia. Clim. Dyn., 31, 449-461, doi: 10.1007/s00382-007-0311-4. [Link]

Maloney, E. D. and M. J. Dickinson, 2003: The intraseasonal oscillation and the energetics of summertime tropical western North Pacific synoptic-scale disturbances. J. Atmos. Sci., 60, 2153-2168, doi: $10.1175 / 1520-0469(2003) 060<2153$ :tioate $>2.0 . c 0 ; 2$. [Link]

Mujumdar, M., B. Preethi, T. P. Sabin, K. Ashok, S. Saeed, D. S. Pai, and R. Krishnan, 2012: The Asian summer monsoon response to the La Nina event of 2010. Meteorol. Appl., 19, 216-225, doi: 10.1002/met.1301. [Link]

Rodionov, S. N., 2004: A sequential algorithm for testing climate regime shifts. Geophys. Res. Lett., 31, L09204, doi: 10.1029/2004GL019448. [Link]

Wang, B. and H. Rui, 1990: Synoptic climatology of transient tropical intraseasonal convection anomalies: 1975-1985. Meteorol. Atmos. Phys., 44, 43-61, doi: 10.1007/bf01026810. [Link] 